\title{
Multiple goal perspective and social identification processes
}

\author{
Smoking should not be examined in isolation, but within the \\ context of the underlying multitude of goals a person is \\ pursuing. Moreover, smoking is represented in how smokers \\ view themselves and linked to the social groups to which \\ they belong. Incorporating these notions to smoking \\ research will enhance smoking cessation efforts.
}

Dimoff \& Sayette [1] make very notable points on the influence of the social context on smoking behaviour that, if applied, will impact significantly upon the future conceptualization of smoking within laboratory research. In this commentary I elaborate on two of the key points they advance.

First, Dimoff \& Sayette state rightfully that smoking is not 'necessarily a failure of self-regulation (p. 10)', as the behaviour may be a means to other ends. Indeed, people always hold multiple goals simultaneously. It is, therefore, important to know the extent to which a specific goal, such as smoking or quitting smoking, interferes with other personal aims or, conversely, facilitates their attainment [2,3]. Seemingly irrational behaviour (e.g. smoking) in terms of one goal (e.g. being healthy) may be very logical from the perspective of the attainment of another valued goal (e.g. to be appreciated by friends). This multiple goal perspective also entails that a health goal, such as the wish to quit smoking, can impact upon actual behaviour only when the goal is always prioritized, and is shielded from potentially strong influences of other goals [4]. If not, self-regulatory behaviour with regard to another-possibly incompatible - goal will occur. In short, health goals, such as (quitting) smoking, are part of the myriad of personal goals, and their position relative to other goals should be known to effectively understand, predict and influence (smoking) behaviour [5].

Second, people are more likely to behave in line with how they perceive themselves to be, rather than act in conflict with central self-views [6,7]. Some theorists even state that all behaviour is instigated to reinforce or enhance a 'sense of self' [8,9]. In other words, beliefs about 'the person one is' are likely to affect behavioural choices strongly. Moreover, behaviour that is recurrent, such as smoking, becomes integrated into the identity of a person (e.g. 'smoking-type or person') and, as a result, is more robust to change. One striking example is that mothers who have quit smoking successfully during pregnancy frequently return to smoking after their baby is born, out of a 'nostalgia' reasons or, in other words, to become their former, free, independent and less stressed 'self' [10]. Consequently, to establish enduring change, it seems important that smokers can develop new self-representations in which they can see themselves as non-smokers or 'quitters' [11], and that these self-images appear compatible with other existing identities [12].

Some recent models work from this notion by forwarding the idea that a new transitional identity which is shared by the social environment, such as the recovery addict', is helpful for people who are trying to quit smoking (e.g. the Social Identity Model of Cessation Maintenance [13] and the Social Identity Model of Recovery [14]). Naturally, in daily life, carrying out such a 'new' identity may not be easy: Dimoff \& Sayette underscore the fact that social identity is derived from group membership and accompanying social norms [15], and that most smokers have strong social connections with other people who smoke. This makes the question of how smokers can quit smoking, and still remain a valued member of the own social group of smokers, a somewhat pressing one. Although research on this particular topic in the field of smoking cessation is lacking, some ideas in this regard may be derived from studies in the field of social psychology; for example, on upward social mobility [16].

Summarizing, the authors have made a compelling statement for the necessity of incorporating social aspects when studying smoking behaviour in the laboratory. Irrespective of the physiological processes that certainly also play a considerable role, smoking is indeed in essence a social behaviour for all people who smoke. Mapping smokers' goals and tapping into social identification processes in research on smoking, therefore, is pivotal.

\section{Declaration of interests}

None.

Keywords Goal conflict, identity, multiple goals, quitting process, smoking, social identification.

WINIFRED A. GEBHARDT

Health, Medical and Neuropsychology,

Leiden University, the Netherlands

E-mail: gebhardt@fsw.leidenuniv.nl

\section{References}

1. Dimoff, J., Sayette, M. The case for investigating social context in laboratory studies of smoking. Addiction 2016; DOI: 10.1111/add.13503. 
2. Maes S., Gebhardt W. A. Self-regulation and health behaviour: the health behaviour goal model. In: Boekaerts M., Pintrich P. R., Zeidner M., editors. Handbook of Self-Regulation. San Diego, CA: Academic Press; 2000, pp. 343-68.

3. Riediger M., Freund A. M. Interference and facilitation among personal goals: Differential associations with subjective well-being and persistent goal pursuit. Pers Soc Psychol Bull 2004; 30: 1511-23.

4. Shah J. Y., Friedman R., Kruglanski A. W. Forgetting all else: on the antecedents and consequences of goal shielding. J Pers Soc Psychol 2002; 83: 1261.

5. Gebhardt W. A. Contextualizing health behaviors: the role of personal goals. In: de Ridder D., de Wit J., editors. Self-regulation in Health Behavior. Chichester, UK: John Wiley \& Sons; 2006, pp. 27-43.

6. Mann T., de Ridder D., Fujita K. Self-regulation of health behavior: social psychological approaches to goal setting and goal striving. Health Psychol 2013; 32: 487.

7. Kwasnicka D., Dombrowski S. U., White M., Sniehotta F. Theoretical explanations for maintenance of behaviour change: a systematic review of behaviour theories. Health Psychol Rev 2016; 10: 277-96.

8. Stets J. E., Burke P. J. Identity theory and social identity theory. Soc Psychol Q 2000; 63: 224-37.

9. Sedikides C., Strube M. J. Self-evaluation: to thine own self be good, to thine own self be sure, to thine own self be true, and to thine own self be better. Adv Exp Soc Psychol 1997; 29: 209-69.

10. Bottorff J. L., Johnson J. L., Irwin L. G., Ratner P. A. Narratives of smoking relapse: the stories of postpartum women. Res Nurs Health 2000; 23: 126-34.

11. Meijer E., Gebhardt W. A., Van Laar C., Kawous R., Beijk S. C. Socio-economic status in relation to smoking: the role of (expected and desired) social support and quitter identity. Soc Sci Med 2016; 162: 41-9.

12. Iyer A., Jetten J., TsivrikosD., Postmes T., Haslam S. A. The more (and the more compatible) the merrier: multiple group memberships and identity compatibility as predictors of adjustment after life transitions. Br J Soc Psychol 2009; 48: 707-33.

13. Frings D., Albery I. P. The social identity model of cessation maintenance: formulation and initial evidence. Addict Behav 2015; 44: 35-42.

14. Best D., Beckwith M., Haslam C., Alexander Haslam S., Jetten J., Mawson E. et al. Addict Res Theory 2016; 24: 111-23.

15. Tajfel H., Turner J. C. An integrative theory of intergroup conflict. In: Austin W. G., Worchel S., editors. The Social Psychology of Intergroup Relations. Monterey, CA: Brooks-Cole; 1979, pp. 33-47.

16. Van Laar C., Bleeker D., Ellemers N., Meijer E. Ingroup and outgroup support for upward mobility: divergent responses to ingroup identification in low status groups. Eur J Soc Psychol 2014; 44: 563-77. 